\title{
Frequency of headache among university students and its effect on daily living activities
}

\author{
${ }^{1}$ Ruhsen Ocal, ${ }^{1}$ Ilkin Iyigundogdu, ${ }^{2}$ Nazli Gursoy Kirnap, ${ }^{3}$ Irem Talu, ${ }^{3}$ Defne Alkislar, \\ ${ }^{3}$ Dilay Aras, ${ }^{3}$ Aylin Uner, ${ }^{3}$ Ece Uzunalioglu \\ ${ }^{1}$ Department of Neurology, Faculty of Medicine, Baskent University; ${ }^{2}$ Department of Internal Medicine, \\ Division of Endocrinology and Metabolism, Faculty of Medicine, Baskent University; ${ }^{3}$ Faculty of \\ Medicine, Baskent University, Ankara, Turkey
}

\begin{abstract}
Background \& Objective: Headache is a common symptom in the general population. The aim of this study was to investigate the frequency of headache among a university students population in Ankara, Turkey; and to evaluate the factors affecting the headache and the effect of headache on students' quality of life. Methods: A face-to-face questionnaire was applied to all participants in the study. In the questionnaire, demographic data, personal background and family history of the participants as well as the presence of headache were collected. The characteristic features of the headache, accompanying symptoms and medication use for the headache were evaluated. The 36-Item Short Form Survey (SF-36), Beck depression and Beck anxiety scales were administered to all participants. Results: Three hundred and sixty six university students participated in the study. Three hundred and thirty one participants $(90.4 \%)$ had experienced headache at least once in their lifetime. Headache was more common in women ( $\mathrm{p}<0.01)$. Depression was found in $135(36.9 \%)$ students with the Beck depression scale, and anxiety was found in $236(64.5 \%)$ students with the Beck anxiety scale. There was no relationship between depression or anxiety and the presence of headache $(p>0.05)$. Emotional role difficulties, social function, pain and general health scores were significantly lower on SF-36 in the group with headache $(\mathrm{p}<0.05)$ than without headache.

Conclusion: Headache adversely affects the quality of life and is a common symptom among university students, independent of depression and anxiety.
\end{abstract}

Keywords: Headache; depression; anxiety; daily living activities

\section{INTRODUCTION}

Headache is one of the most common symptoms seen in the general population. In a review, when studies published between 1990 and 2007 were examined, the prevalence of headache up to the age of 20 was found to be $58.4 \% .^{1}$ Consistent results have not been obtained in headache prevalence studies. In a study conducted among medical students, one-year headache prevalence was found to be $89.6 \%$. This study found that headache significantly affected students' academic and social life. ${ }^{2}$ In another study conducted with university students, the prevalence of headache was found to be $87.2 \%$. $^{3}$

There are numerous factors that are associated with headaches.-6 Depression and anxiety disorders may accompany headache. ${ }^{4}$ There is only one study investigating the effect of smartphone use, computer use, time spent in front of the screen, and headphone use on headache frequency. ${ }^{5} \mathrm{We}$ investigated the frequency of the headache in university students and evaluated the factors affecting the headache frequency as well as the effects of headache on daily life activities in a university student population in Ankara, Turkey.

\section{METHODS}

This research was approved by the Medical and Health Sciences Ethics Committee of Baskent University (KA19/359) and supported by the Research Fund of Baskent University. The study was voluntary, and informed consent was given by Baskent University students who were included in the study. A face-to-face questionnaire was administered to all participants. In the questionnaire, demographic data, personal

Address correspondence to: Ruhsen Ocal, Baskent University, Faculty of Medicine, Department of Neurology, Ankara, Turkey. Tel no: +90 31220368 68. E-mail: ruhsenocal@yahoo.com

Date of Submission: 31 March 2021; Date of Acceptance: 2 June 2021

https://doi.org/10.54029/2021wdk 
background and family history of the participants were collected. The presence of drug and food allergy including urticaria, rhinitis, conjunctivitis, angioedema, bronchospasm and anaphylaxis immediately after (1-6 hours ) exposure was sought in participants. The total hours spent by the students on lessons per week were recorded. Participants were asked whether they experienced headache or not. Headache characteristics, accompanying symptoms and medication use were recorded in those who had headache. The Beck depression and Beck anxiety scales were administered to all participants. ${ }^{78}$ Turkish validity and reliability studies of both these scales were conducted. ${ }^{9,10}$ Daily living activities were evaluated in all participants with the SF-36 questionnaire which had previously been validated for a Turkish population. ${ }^{11,12}$

\section{Statistical analysis}

Statistical analysis was done with SPSS version 22. The distribution of the data was evaluated with the Kolmogorov-Smirnov test. Parametric data with normal distribution was expressed as mean \pm standard deviation (SD). Student's $\mathrm{t}$-test was used to compare parametric groups in independent groups. Chi-square test was used to compare categorical data in independent groups. $\mathrm{P}<0.05$ was considered statistically significant.

\section{RESULTS}

A total of 366 volunteer university students participated in the study. Two hundred and thirty six participants $(64.5 \%)$ were women and 130 participants $(35.5 \%)$ were men (Table 1$)$. The mean age of the participants was $20.5 \pm 2.13$ years. Headache was present in $331(90.4 \%)$ participants. There was no significant difference in the total weekly lesson hours between the groups with and without headache $(\mathrm{p}=0.82) .94 .9 \%(\mathrm{n}=224)$ of the female participants and $82.3 \%$ of male participants $(n=107)$ had experienced headache and headache was significantly more common in female participants $(\mathrm{p}<0.01)$.

Two hundred and eighteen participants (59.7\%) did not use analgesic drugs during the headache attack; 148 (40.3\%) participants used analgesic medications. The most common medication used during the headache attack was paracetamol $(n=34)$, and the second most common therapy was ibuprofen $(n=22)$.

Depression was found in 135 (36.9\%) students in the Beck depression scale, and anxiety was found in $236(64.5 \%)$ students in the Beck anxiety scale (Table 2). There was no relationship between depression $(\mathrm{p}=0.98)$ and anxiety $(\mathrm{p}=0.51)$ and the frequency of headache in the participants.

One hundred and twenty eight participants had a history of allergy including urticaria, rhinitis and conjunctivitis; but bronchospasm, anaphylaxis and angioedema were not found. $97.7 \%$ of these cases had headache, and headache was statistically more common in patients with allergy than those without $(p=0.004)$. However, detailed drug and food allergy were not determined in patients and the allergy types were not defined.

The frequency of headache was not statistically different in the groups with a history of head trauma and without $(\mathrm{p}=0.07)$. In addition, the frequency of headache was found to be similar between the groups who had visual impairment and who were using eye glasses or contact lenses and those without visual impairment $(\mathrm{p}=0.54)$. The frequency of headache was found to be similar between the students living with their families and those living alone $(\mathrm{p}=0.84)$. The frequency of headache was found to be similar between the groups that were using alcohol, substance or smoking, and the groups that were not $(\mathrm{p}=0.4$, $\mathrm{p}=0.6, \mathrm{p}=0.28)$. Personality characteristics did not have an effect on headache frequency $(\mathrm{p}=0.15)$. Daily time spent on exercise, using a mobile phone, spent in front of a screen, and using headphones were found to be similar in the groups with and without headache $(\mathrm{p}=0.25$, $\mathrm{p}=0.17, \mathrm{p}=0.81, \mathrm{p}=0.51)$. The relationship between the frequency of headache and these variables is shown in Table 3.

When the groups with and without headache were evaluated, the physical function, physical role difficulty, energy and mental health scores of the group with and without headache were similar $(\mathrm{p}=0.24, \mathrm{p}=0.052, \mathrm{p}=0.76, \mathrm{p}=0.84)$. However,

Table 1: Gender of the participants

\begin{tabular}{ll}
\hline & $\mathbf{n}(\mathbf{\%})$ \\
\hline Female & $236(64.5 \%)$ \\
Male & $130(35.5 \%)$ \\
\hline Total & $366(100 \%)$ \\
\hline
\end{tabular}


Table 2: Presence of certain symptoms among participants

\begin{tabular}{lcc}
\hline & $\begin{array}{c}\text { Presence among participants } \\
\mathbf{n}(\%)\end{array}$ & $\begin{array}{c}\text { Absence among participants } \\
\mathbf{n}(\%)\end{array}$ \\
\hline Headache & $331(90.4 \%)$ & $35(9,6 \%)$ \\
Depression & $135(36.9 \%)$ & $231(63.1 \%)$ \\
Anxiety & $236(64.5 \%)$ & $130(35.5 \%)$ \\
\hline
\end{tabular}

emotional role difficulties, social function, pain, and general health scores were significantly lower in the group with headache. $(\mathrm{p}=0.01, \mathrm{p}=0.025$, $\mathrm{p}=0.001, \mathrm{p}=0.038$ ).

\section{DISCUSSION}

Headache prevalence in children and adolescents varies in different studies. ${ }^{1,2}$ In our study, the prevalence of headache was found to be $90.4 \%$. Previous studies have generally focused on oneyear headache prevalence, and the age group evaluated ranged between 5-20 years. We attribute the fact that headache has a higher prevalence among university students to increased awareness of the condition in individuals with a older age.

Similar to previous studies, headache was found more frequently in females in our study $(\mathrm{p}<0.01))^{4,5}$ In our study, we found that paracetamol and ibuprofen were the commonest and second commonest analgesics used by our study population. This is in accord with the common usage of paracetamol in other studies, ${ }^{5,6}$ In another study, the second most commonly used drug was acetylsalicylic acid. ${ }^{6}$
In previous studies, headache was more frequent in individuals with high stress, sleep disturbance and abnormal anxiety levels. ${ }^{6}$ Stress and depression were also observed to be associated with the frequency of headache in another study. ${ }^{4}$ This is in contrast to our finding that stress, sleep disorders, depression and anxiety did not affect headache frequency.

We found that headache frequency was only related to a history of allergy $(p=0.004)$. We did not find a relationship between headache frequency and head trauma, use of eye glasses, use of contact lenses, alcohol consumption, smoking, substance use, daily exercise duration, duration of mobile phone use, duration of headphone use or time spent in front of screens. In contrast to our study in a previous report, it was found that the time spent in front of screens affected the frequency of headache. ${ }^{6}$

We could not find a relationship between headache frequency and social activity, economic conditions or personality traits in our study group. We did not find any other study investigating the effect of headache on daily life activities in

Table 3: The relationship between the frequency of headache and the variables

\begin{tabular}{lc}
\hline Variable & $\mathbf{p}$ value \\
\hline History of head trauma & $\mathrm{p}=0.07$ \\
Presence of visual impairment & $\mathrm{p}=0.54$ \\
Living with family & $\mathrm{p}=0.84$ \\
Alcohol consumption & $\mathrm{p}=0.4$ \\
Other substance consumption & $\mathrm{p}=0.6$ \\
Cigarette consumption & $\mathrm{p}=0.28$ \\
Personality characteristics & $\mathrm{p}=0.15$ \\
Depression & $\mathrm{p}=0.98$ \\
Anxiety & $\mathrm{p}=0.51$ \\
Daily time spent on exercise & $\mathrm{p}=0.25$ \\
Daily time spent in front of a screen & $\mathrm{p}=0.81$ \\
Daily time spent using a mobile phone & $\mathrm{p}=0.17$ \\
Daily time spent using headphones & $\mathrm{p}=0.51$ \\
\hline
\end{tabular}


university students using an objective pain scale. Daily living activities were evaluated with the SF-36 questionnaire. When the groups with and without headache were evaluated, the physical function, difficulty in performing physical roles, energy and mental health scores of the group with and without headache were similar. However headache was found more frequent in students who had lower scores on difficulty in performing emotional roles, social function, pain, and general health scores in the SF-36 questionnaire.

In conclusion, headache is very common among a university student population in Turkey, and has a female predominance. It affects the daily life activities and performance of the students as well as their social and emotional health. Therefore we think that screening for the presence of headache, and effective headache management are likely to improve their quality of life.

\section{DISCLOSURE}

Financial support: None

Conflict of interest: None

\section{REFERENCES}

1. Abu-Arafeh I, Razak S, Sivaraman B, et al. Prevelance of headache and migraine in children and adolescents: A systematic review of population-based studies. Dev Med Child Neurol 2010;52:1088-97.

2. Khairoalsindi OA, Saber WK, Althubaiti NA, Alshareef EF, Almekhlafi MA. Primary headache characters and coping strategies among medical students of Umm Al-Qura University in the Western region of Saudi Arabia. Neurosciences 2018;23(4):308-13.

3. Souza-e-Silva HR, Rocha-Filho PA. Headaches and academic performance in university students: a cross-sectional study. Headache 2011; 51:1493-502.

4. Desouky DE, Zaid HA, Taha AA. Migraine, tensiontype headache, and depression among Saudi female student in Taif University. J Egypt Public Health Assoc 2019;94(1):7.

5. Montagni I, Guichard E, Carperet C, Tzourio C, Kurth $\mathrm{T}$. Screen time exposure and reporting of headaches in young adults: A cross-sectional study. Cephalalgia 2016;36(11):1020-7.

6. Nandha R, Chhabra MK. Prevalence and clinical characteristics of headache in dental students of a tertiary care teaching dental hospital in Northern India. Int J Basic Clin Pharmacol 2013;2(1):51-5.

7. Beck AT, Ward CH, Mendelson M, Mock J, Erbaugh J. An inventory for measuring depression. Arch Gen Psychiatry 1961(4):561-71.

8. Beck AT, Ebstein N, Brown G, Steer RA.An inventory for measuring clinical anxiety: psychometric properties. J Consult Clin Psychol 1998;56(6):893-7.

9. Hisli N. Beck depresyon envanteri üniversite öğrencilerinde geçerlilik. Psikoloji Dergisi 1989;7(23):3-13.

10. Ulusoy M, Sahin NH, Erkmen H. Turkish version of the Beck Anxiety Inventory: Psychometric properties. J Cognitive Psychotheraphy 1998;12:2.

11. Ware JE, Sherbourne CD. The MOS 36-item shortform health survey (SF-36). I. Conceptual framework and item selection. Med Care 1992;30:473-83.

12. Kocyigit H, Aydemir O, Fisek G, Olmez N, Memis A. Kısa form-36 (KF-36)'nın Türkçe verisyonunun güvenilirliği ve geçerliliği. İlaç ve Tedavi Dergisi 1999;12:2:102-6. 